1

2

3

4

5

6

17

(

\title{
G-quadruplex formation on specific surface-exposed regions of the human ribosomal RNA
}

Santi Mestre-Fos ${ }^{1}$, Petar I. Penev ${ }^{2}$, Suttipong Suttapitugsakul ${ }^{1}$, Chieri Ito ${ }^{1}$, Anton S. Petrov ${ }^{1}$, Roger M. Wartell ${ }^{2}$, Ronghu $\mathrm{Wu}^{1}$ and Loren Dean Williams ${ }^{1,2 \dagger}$

${ }^{1}$ School of Chemistry and Biochemistry, Georgia Institute of Technology,

Atlanta, GA 30332-0400, USA.

${ }^{2}$ School of Biological Sciences, Georgia Institute of Technology, Atlanta, GA 30332-0400, USA

Running title: G-quadruplexes on the human $28 S$ rRNA

$\dagger$ To whom correspondence may be addressed. Email:

loren.williams@chemistry.gatech.edu

Keywords: rRNA, expansion segments, G-tracts, chordates, helicases.

9

(1)

1

2

33


G-quadruplexes on the human 28S rRNA

\section{ABSTRACT:}

Profound similarities and critical differences mark ribosomes across phylogeny. The ribosomal core, approximated by the prokaryotic ribosome, is universal, yet mammalian 8 ribosomes are nearly twice as large as those of prokaryotes. Differences in size are due in 9 part to rRNA expansion segments. Here we show rRNA tentacles of Expansion Segment 7 (ES7) of Homo sapiens can form G-quadruplexes in vitro. G-quadruplex-forming regions are

11 located on the most surface-exposed regions of the ribosome, near the termini of rRNA 12 tentacles. We characterized rRNA of the large ribosomal subunit by computation, circular dichroism, gel mobility, fluorescent probes, nuclease accessibility, electrophoretic mobility shifts and blotting. We investigated ES7 and oligomers derived from ES7, intact 28S rRNA, and $80 \mathrm{~S}$ ribosomes and polysomes. We used mass spectrometry to identify proteins that bind to rRNA G-quadruplexes in cell lysates. Proteins that associate with rRNA Gquadruplexes include helicases (DDX3, CNBP, DDX21, DDX17) and heterogeneous nuclear ribonucleoproteins (hnRNPs). And finally, by multiple sequence alignments, we observed that G-quadruplex-forming sequences appear to be a general feature LSU rRNA of the phylum Chordata but not in other phyla. It is known that G-quadruplexes form in telomeres, promoters, and untranslated regions of mRNA but, to our knowledge, they have not been reported previously in ribosomes. 
G-quadruplexes on the human 28S rRNA

\section{INTRODUCTION}

Cytosolic ribosomes of essentially all extant species contain a 'common core' [1] consisting of rRNA and rProteins with universal structure and function. Common core rRNA is reasonably approximated by prokaryotic rRNA; around $90 \%$ of prokaryotic rRNA is contained in the common core.

Eukaryotic ribosomes contain additional rRNA and rProteins that form a secondary shell. The rRNA component of the eukaryotic shell contains expansion segments (ESs) that attach to the common core at a handful of specific sites [2-5]. ESs are the most variable rRNA structures over phylogeny, and are known in yeast to play roles in ribosome biogenesis [6] and to bind to chaperone proteins [7, 8]. In chordates, ESs form tentacles (Figure 1) that can extend for hundreds of Ångstroms from the ribosomal surface [9]. The lengths of the tentacles are significantly elongated in mammals and reach a zenith in primates and birds.

Here, we observe the terminal regions of rRNA tentacles of human expansion segments 7 and 27 (ES7 $7_{\mathrm{HS}}$ and ES27 $7_{\mathrm{HS}}$ ) contain sequences that can form G-quadruplexes. Gquadruplexes are favored by tandem G-tracts separated by short non-specific sequences. ES7 $7_{\mathrm{HS}}$ contains ten tandem G-tracts in one tentacle and four in another. ES27 $7_{\mathrm{HS}}$ contains six tandem G-tracts in tentacle $a$, two groups of three tandem G-tracts in tentacle $b$, and four in helix 63 (Table 1). To investigate G-quadruplex formation in ES7HS, we used computation, circular dichroism, gel mobility, fluorescent probing, nuclease accessibility, electrophoretic mobility shift assays (EMSA), dot blotting, Western blotting, and pull-down assays combined with stable isotope labeling with amino acids in cell culture (SILAC) and Mass Spectroscopy. We also performed Multiple Sequence Alignments (MSAs) and database analysis.

Our results indicate that G-quadruplexes can form in a series of model systems including the isolated tandem G-tracts of $E S 7_{\mathrm{HS}}$, in intact $\mathrm{ES} 7_{\mathrm{HS}}$ and in purified human $28 \mathrm{~S}$ rRNA. Our data also provide evidence for the formation of G-quadruplexes in $80 \mathrm{~S}$ ribosomes and polysomes. Pull-down assays show that known G-quadruplex-binding proteins associate with the G-tracts of ES7 $7_{\mathrm{HS}}$. The MSA analyses indicate that G-quadruplexforming sequences are found in ES7s of all chordate species. 
1

2

3

4

5
Nucleotides

Table 1. G-quadruplex-forming regions within ES7 and ES27 rRNA

ES7

587-648

583-644

627-656

$557-594$

829-849

816-836

907-932

933-958

Gallus gallus

GGGGCGCGGGGGCGGGGGGGGUCGGG

3095-3149

$3373-3422$

\section{helix 63}

Homo sapiens

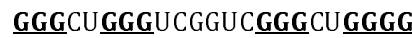

2896-2918

a. This sequence falls outside the $\mathrm{G}_{\geq 3} \mathrm{~N}_{1-7} \mathrm{G}_{\geq 3} \mathrm{~N}_{1-7} \mathrm{G}_{\geq 3} \mathrm{~N}_{1-7} \mathrm{G}_{\geq 3}$ motif

G-quadruplexes have been shown previously to cluster within regulatory RNAs such

8 as 52 and 3? untranslated regions of mRNAs [10] and with the first intron [11]. To our

9 knowledge, this study is the first report of G-quadruplex formation in any ribosomal RNA,

10 which constitutes over $80 \%$ of cellular RNA. 


\section{G-quadruplexes on the human 28S rRNA}

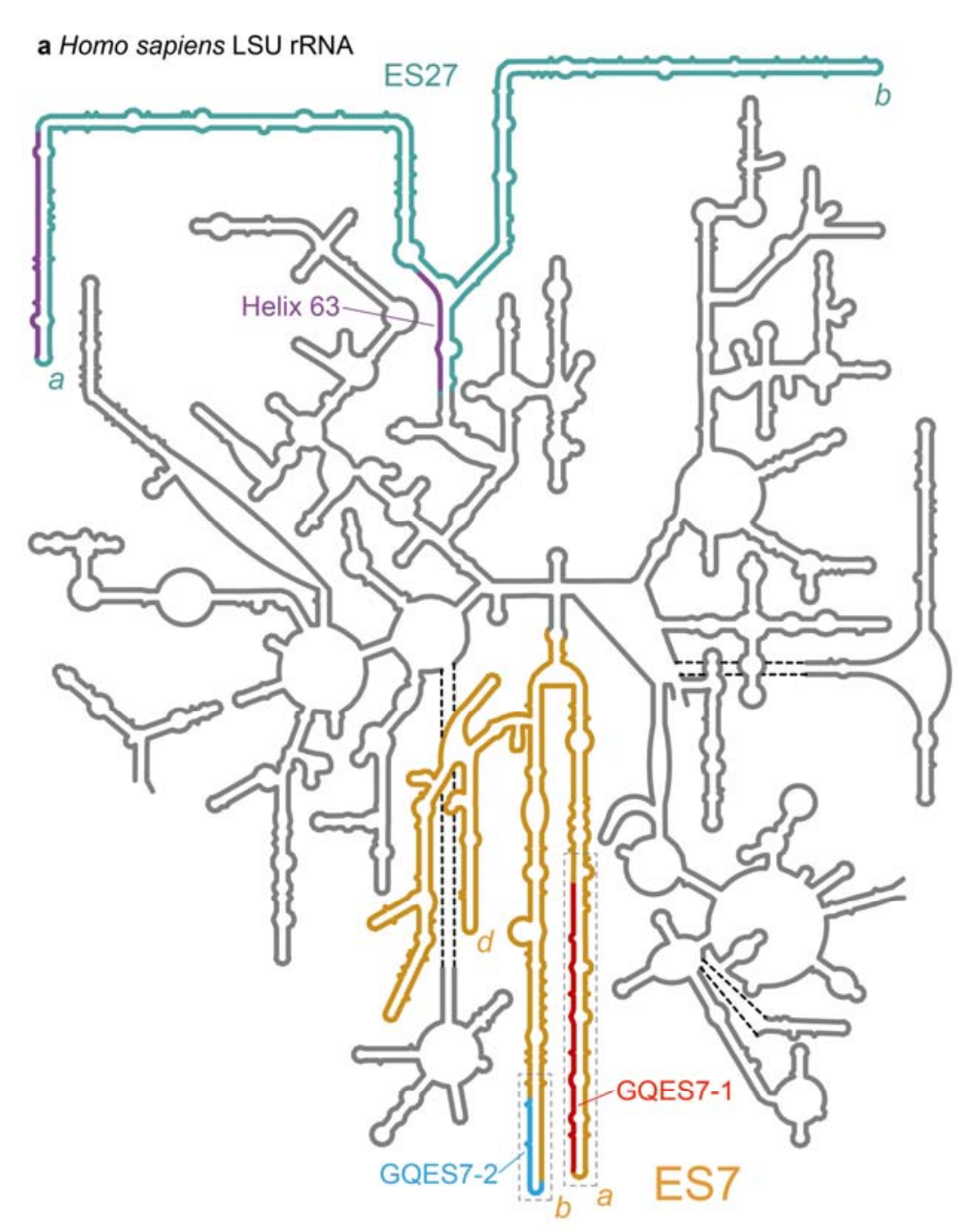

Figure 1. Model secondary structure of the LSU rRNA of Homo sapiens. Potential G-quadruplexforming regions (defined by $\mathrm{G}_{\geq 3} \mathrm{~N}_{1-7} \mathrm{G}_{\geq 3} \mathrm{~N}_{1-7} \mathrm{G}_{\geq 3} \mathrm{~N}_{1-7} \mathrm{G}_{\geq 3}$ ) are highlighted. a) Expansion segment ES7 $7_{\mathrm{HS}}$ is orange. Tentacles $a, b$ and $d$ of ES7 ${ }_{\mathrm{HS}}$ are indicated. G-quadruplex-forming regions GQES7-1 (red) and GQES7-2 (cyan) are highlighted. Expansion segment ES27 $7_{\mathrm{HS}}$ is green with purple G-tracts. Helix 63 , at the base of ES27 $7_{\mathrm{HS}}$, contains a G-quadruplex motif (purple). Tentacles $a$ and $b$ of ES27 $7_{\mathrm{HS}}$ are indicated. b) An expanded view of GQES7-2 indicates the sequence. c) An expanded view of GQES71.

\section{RESULTS}

ES7 and ES27 of the human LSU contain putative G-quadruplex sequences. The

12 propensity of an RNA to form G-quadruplexes can be roughly predicted by numbers and

13 lengths of guanine tracts and the lengths and compositions of loops. The program QGRS

14 Mapper [12] provides "G-scores", which quantitate this propensity. We have identified ES7 
G-quadruplexes on the human 28S rRNA

1 and ES27 as the only human LSU rRNA regions containing sequences reasonably capable of

2 forming these secondary structures. Our computational results suggest that G-

3 quadruplexes can form in the guanine-rich strands at the termini of the longest rRNA

4 tentacles of these two ESs. In tentacles $a$ and $b$ of ES7 ${ }_{\mathrm{HS}}$, two regions, here named GQES7-1

5 and GQES7-2 (Figure 1), meet the G-quadruplex consensus $\left(\mathrm{G}_{\geq 3} \mathrm{~N}_{1-7} \mathrm{G}_{\geq 3} \mathrm{~N}_{1-7} \mathrm{G}_{\geq 3} \mathrm{~N}_{1-7} \mathrm{G} \geq 3\right.$ ). The

6 G-scores of GQES7-1 and GQES7-2 are in the range of well-established RNA G7 quadruplexes.

1, Figure 1, Table 1) gives a G-score of 60. The sequence 5' GGGUGCGGGGGUGGGCGGG 3'

11 GGGAGGGCGCGCGGGUCGGGG 3' (nts 829-849 within GQES7-2, Figure 1, Table 1) gives a G-

12 score of 38. The difference between the G-scores of GQES7-1 and GQES7-2 suggests more

13 stable and/or more extensive G-quadruplex formation in GQES7-1 than in GQES7-2. A

14 greater propensity of GQES7-1 over GQES7-2 for G-quadruplex formation is seen in all

15 experiments below.

16 As a positive control for our computations and experiments, we used the ADAM10

17 G-quadruplex. This stable and well-characterized G-quadruplex-forming RNA, found in the

18 5'-UTR of the mRNA of ADAM10 metalloprotease [13], gives a G-score of 42. As negative

19 controls, we used two mutant RNA oligomers ( $m t E S 7-1$ and $m t E S 7-2$ ) that are analogous to

20 GQES7-1 and GQES7-2 in composition and length, with disrupted G-tracts (Table S.1).

21 Neither gives a G-score.

22 Near the terminus of human ES27 (ES27 $7_{\mathrm{HS}}$, Figure 1, Table 1), the sequence 5'

23 GGGGAGAAGGGUCGGGGCGGCAGGG 3' (nts 3124-3148, tentacle a) gives a G-score of 40.

$24 \mathrm{ES}_{27} 7_{\mathrm{HS}}$ also contains a putative G-quadruplex-forming region in Helix 63 near the junction

25 of two tentacles. In this study, we focused only ES7 $7_{\mathrm{HS}}$. However, based on the high

26 correlation of G-scores and our experimental observation of G-quadruplexes within ES7 $7_{\mathrm{HS}}$,

27 we expect G-quadruplexes to also form in ES27 $\mathrm{HS}$.

28 We investigated the ability of the two regions within ES7 $7_{\mathrm{HS}}$ (GQES7-1 and GQES7-2,

29 Figure 1) to form G-quadruplexes in vitro by several methods. 
ThT fluorescence. ThT is known to yield intense fluorescence at $487 \mathrm{~nm}$ upon association with G-quadruplexes $[14,15]$. ThT results here suggest formation of Gquadruplexes in GQES7-1, GQES7-2 and intact ES7 HS $_{\text {in }}$ the presence of $\mathrm{K}^{+}$, the monovalent

4 ion thought to stabilize G-quadruplexes (Figure 2a). The signal for GQES7-2 is attenuated 5 compared to that of GQES7-1. This difference, which suggests less stable G-quadruplexes 6 and/or less extensive G-quadruplex formation of GQES7-2, is consistent with the 7 computed propensity and is observed here in a variety of assays. The formation of G8 quadruplexes by GQES7-1, GQES7-2 and intact ES7 $\mathrm{HS}$ is supported by competition assays 9 with pyridostatin (PDS) (Figure 2c and 2d). PDS is a G-quadruplex stabilizer and a ThT 10 competitor with a greater affinity than ThT for G-quadruplexes [16]. In this series of 11 experiments ADAM10 was used as a positive control and $m t$ ES7-1, $m t$ ES7-2 and tRNA 12 were used as negative controls.

13 Circular dichroism. CD has been used widely to study RNA and DNA G14 quadruplexes. Our CD spectra of GQES7-1 and GQES7-2 are consistent with formation of 15 parallel G-quadruplexes based on a characteristic peak at $260 \mathrm{~nm}$ and a trough at $240 \mathrm{~nm}$ 16 [17-21] (Figure 2b). G-quadruplexes are thought to be more stable in $\mathrm{K}^{+}$than in $\mathrm{Li}^{+}$or $\mathrm{Na}^{+}$ 17 [22]. The intensity of the $260 \mathrm{~nm}$ peak of GQES7-1 is attenuated by about 15\% when the monovalent cation is switched from $\mathrm{K}^{+}$to $\mathrm{Na}^{+}$or $\mathrm{Li}^{+}$(not shown). 


\section{G-quadruplexes on the human 28S rRNA}
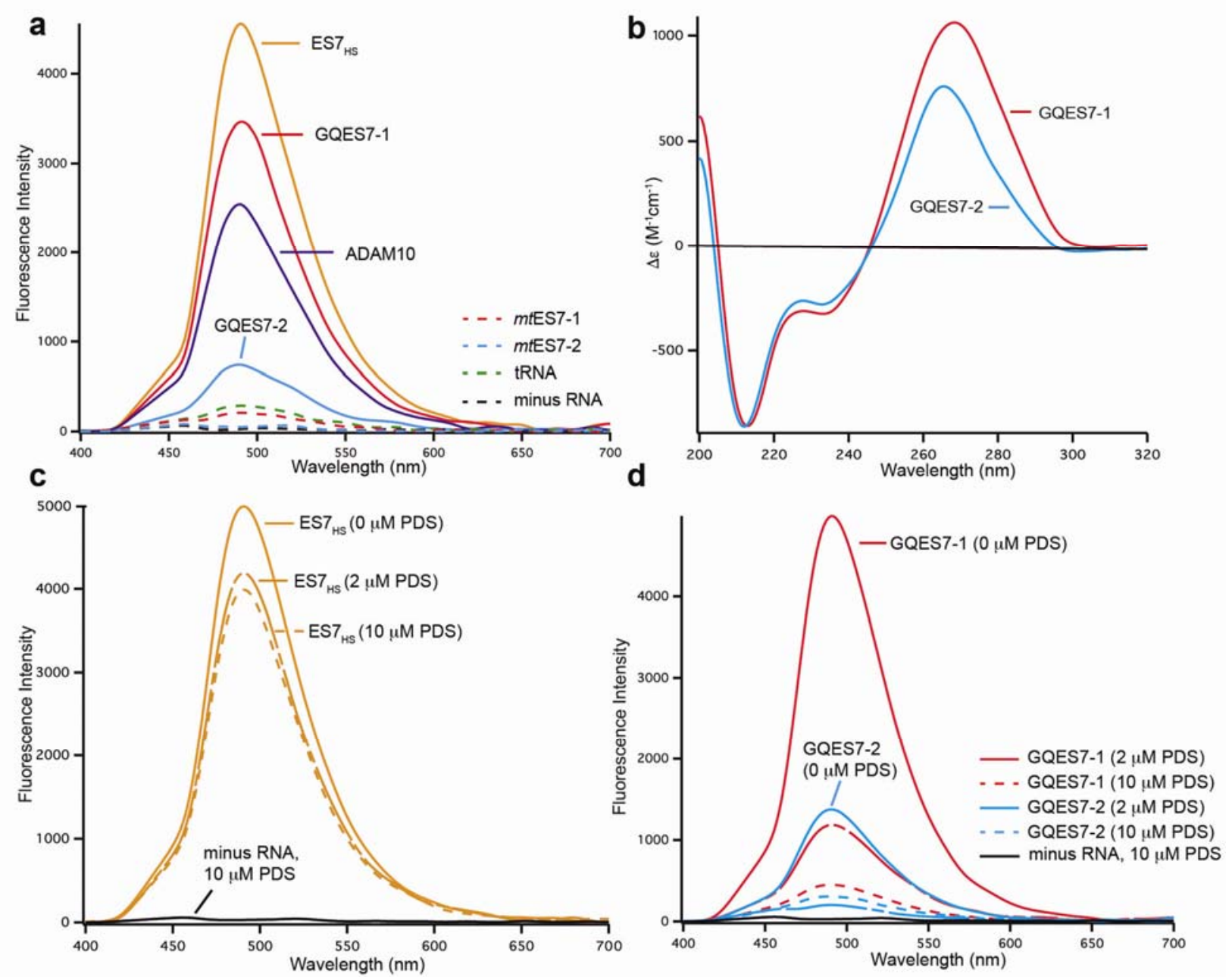

Figure 2. Formation of G-quadruplexes in GQES7-1, GQES7-2, and ES7 ${ }_{\mathrm{HS}}$ a) Fluorescence emission of ThT in the presence of ES7 ${ }_{\mathrm{HS}}$, GQES7-1, GQES7-2, or ADAM10. Negative controls (dashed) are tRNA, $m t$ ES7-1, $m t$ ES7-2 and minus RNA. b) CD spectra of GQES7-1 and GQES7-2. In the presence of ThT, PDS was added to c) intact ES7 ${ }_{\mathrm{HS}}$ and to d) GQES7-1 and GQES7-2.

Gel staining. ThT staining of GQES7-1 and GQES7-2 after native gel electrophoresis

8 in the presence of $\mathrm{Na}^{+}$or $\mathrm{Li}^{+}$or $\mathrm{K}^{+}$is in agreement with the CD data (Figure 3a and 3b). The

9 RNAs are expected to fluoresce within the gel only upon formation of G-quadruplexes.

10 GQES7-1 and GQES7-2 fluoresce more intensely in the presence of $\mathrm{K}^{+}$than in $\mathrm{Na}^{+}$or $\mathrm{Li}^{+}$.

11 Consistent with computation, ThT fluorescence in solution, and CD spectroscopy, GQES7-1

12 forms more extensive G-quadruplexes than GQES7-2 in the gel staining experiments. 

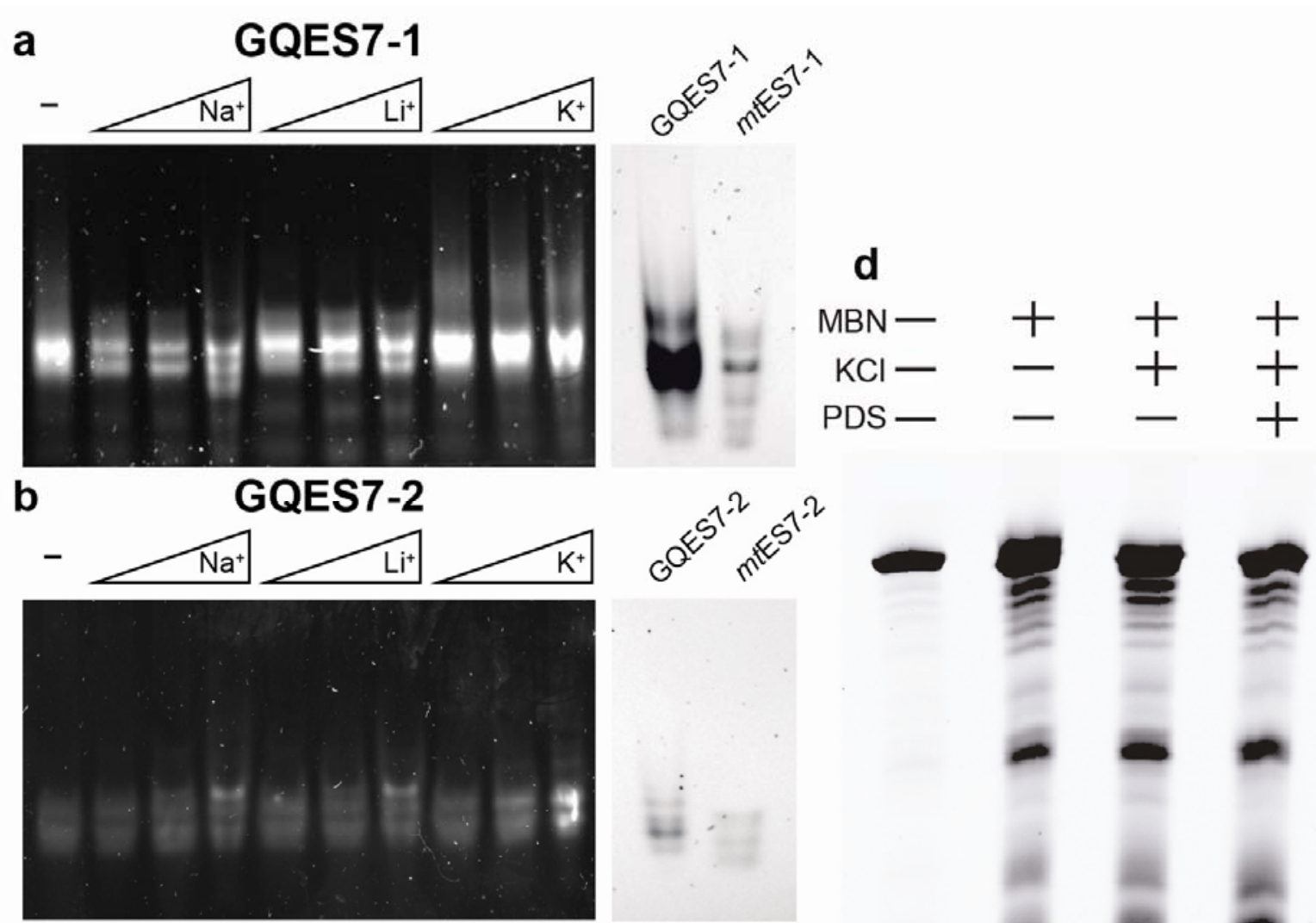

\section{C}
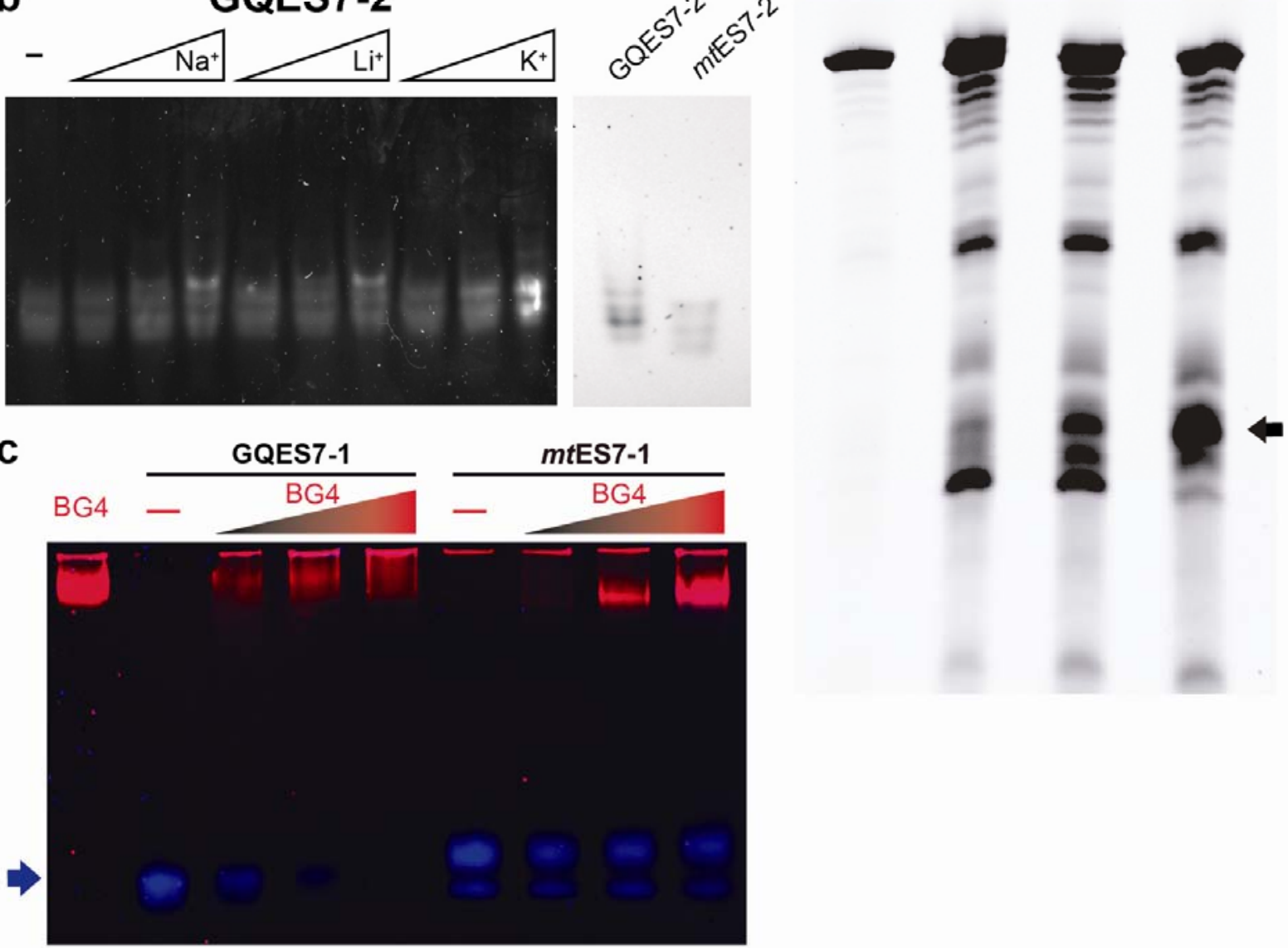

1

Figure 3. The effect of monovalent ion type on G-quadruplex formation. Shown here are a) GQES71 and b) GQES7-2 RNAs with varying concentrations of $\mathrm{Na}^{+}, \mathrm{Li}^{+}$, and $\mathrm{K}^{+}(50,100,250 \mathrm{mM})$, resolved on a native gel stained with ThT. The mutants $m t$ ES7-1 and $m t$ ES7-2 do not fluoresce when stained with ThT, indicating the lack of G-quadruplex formation in these RNAs (gels on the right). c) EMSA of the BG4 antibody with GQES7-1 and its mutant $m t$ ES7-1, visualized on a native gel. GQES7-1 and $m t$ ES7-1 RNAs were loaded at a constant strand concentration with increasing concentrations of

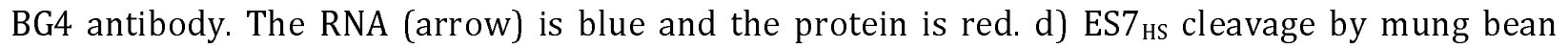
nuclease. ES7 was annealed with or without $\mathrm{KCl}$ and with or without PDS. The black arrow indicates cleaved rRNA. 
Mung bean nuclease cleavage. The regions of 28S rRNA capable of forming Gquadruplexes are opposed by complementary C-rich strands (Figure 1). Upon Gquadruplex formation from duplex rRNA, the C-rich strand would be forced to dissociate to

4 a single strand. To confirm this model, we examined cleavage of ES7 ${ }_{\mathrm{HS}}$ by mung bean nuclease (MBN) (Figure 3d), which preferentially cleaves single-stranded RNA and DNA. The results here show that MBN cleaves ES7 $7_{\mathrm{HS}}$ under G-quadruplex stabilizing conditions to

7 a greater extent than under conditions that destabilize G-quadruplexes (Figure 3d). Addition of $\mathrm{K}^{+}$increases the extent of cleavage and addition of PDS to $\mathrm{K}^{+}$further increases the extent of cleavage. The simplest interpretation of these results is that $\mathrm{ES}_{\mathrm{HS}}$ is dynamic and can exist as a mixture of duplex and G-quadruplex forms. As a negative control, extent of MBN hydrolysis of tRNA did not increase upon addition of $\mathrm{K}^{+}$and/or PDS (Figure S.2).

Antibody binding. BG4 is an antibody developed by Balasubramanian and coworkers $[23,24]$ that binds to a variety of G-quadruplex types but not to other nucleic acids such as RNA hairpins, single-stranded or double-stranded DNA. Here, an EMSA was performed with BG4 to test for G-quadruplex formation in GQES7-1 (Figure 3c). BG4 was also used for dot blotting experiments with GQES7-1, GQES7-2, and intact ES7 $\mathrm{HS}$ (Figure 4).

17 We observe binding of GQES7-1, GQES7-2, and intact ES7 $7_{\mathrm{HS}}$ with BG4. Consistent with the results above, GQES7-1 binds more tightly than GQES7-2 to BG4, which is close to the negative controls (Figure 4a and 4c).

The experiments presented above confirmed that the sequences within human rRNA ES7 of the 28S rRNA are capable of forming G-quadruplexes. We have investigated whether the 28S rRNA obtained from cells could form G-quadruplexes when this RNA is

23 rProtein-free or assembled in ribosomes.

The 28S rRNA was extracted from HEK293T cells and dot blotting was performed with BG4 (Figure 4d). The results indicate that 28S rRNA forms G-quadruplexes in vitro. To confirm that the 28S rRNA is capable of forming G-quadruplexes when assembled in the intact ribosome, dot blotting was also performed with purified $80 \mathrm{~S}$ human ribosomes and 28 polysomes (Figure 4e and 4f).

The results show that the BG4 antibody selectively binds to intact human ribosomes and polysomes in a concentration-dependent manner. PDS enhances binding of the 31 antibody, as expected. The more extensive binding of the antibody to polysomes than to 
1 monomer ribosomes suggests the possibility of formation intermolecular of G-

2 quadruplexes in polysomes.
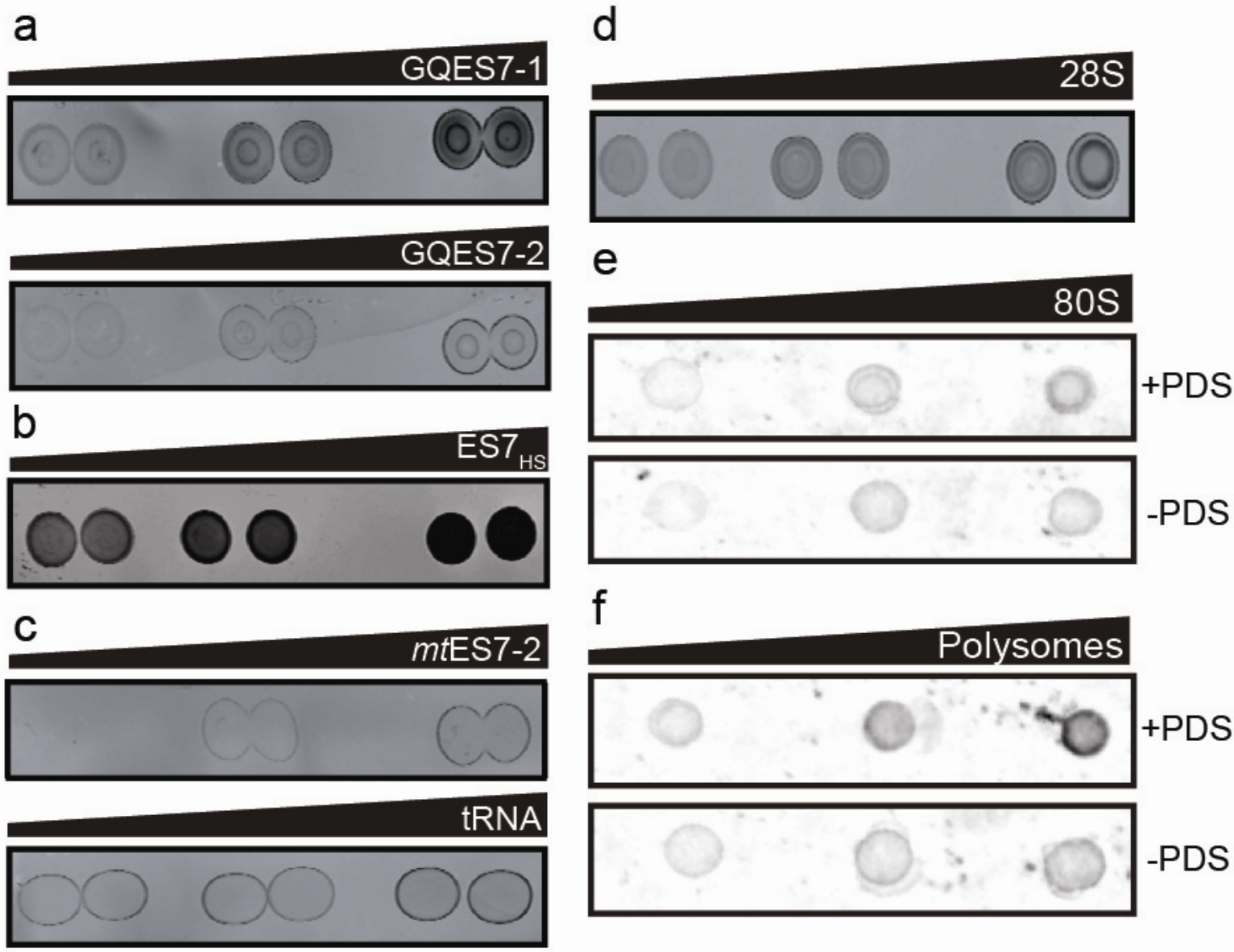

Figure 4. Dot blots performed with the BG4 antibody on a) GQES7-1 and GQES7-2, b) intact ES7 ${ }_{\mathrm{HS}}$ c) the negative controls $m t$ ES7-2 and tRNA, d) the 28S rRNA extracted from HEK293T cells and on e) human $80 \mathrm{~S}$ ribosomes and f) polysomes purified from HEK293 cells. All samples were incubated in the presence of $50 \mathrm{mM} \mathrm{KCl}$ and ribosomes and polysomes were further analyzed with or without $10 \mu \mathrm{M}$ PDS, which stabilizes G-quadruplexes. Samples were loaded onto the membrane in increasing amounts from left to right.

rRNA G-quadruplex-forming sequences are observed throughout the Chordata

phylum. Focusing specifically on translation we have developed the SEREB Database [1],

12 which contains fully curated sequences of rRNAs from all major phyla, yet samples the tree

13 of life in a sparse, efficient and unbiased manner. Here we extended the SEREB database

14 from 10 chordate species to 17 for a fine-grained analysis of ES7.

15 G-quadruplex-forming sequences in chordate ES7s. Our MSA confirms that the lengths

16 of rRNA tentacles of eukaryotes are variable, reaching maxima in species such as G. gallus 
1 and $H$. sapiens. Sequences of the relevant segments of ES7s of various eukaryotes are

2 illustrated in Figure 5, demonstrating the conservation of G-quadruplex-forming sequences

3 motif $\left[\mathrm{G}_{\geq 3} \mathrm{~N}_{1-7} \mathrm{G}_{\geq 3} \mathrm{~N}_{1-7} \mathrm{G}_{\geq 3} \mathrm{~N}_{1-7} \mathrm{G}_{\geq 3}\right.$ (number of $\mathrm{G}$ tracts $(\mathrm{n})>3$ )] and their preferential locations

4 near the termini of tentacles. The number of tandem G-tracts in tentacle a of ES7 is ten in

5 human and chimpanzee and eight in rat and chicken. Fish reptiles and amphibians appear

6 to lack the G-tract motif described here. However, G-tracts outside of the motif can form G-

7 quadruplexes [25, 26]. It is possible that G-tracts with $\mathrm{n}<4$ form intermolecular G-

8 quadruplexes with other tentacles or with other ribosomes as in polysomes.

9 G-quadruplex-forming sequences in chordate ESs other than ES7. Our analysis of the

10 extended SEREB Sequence Database suggests that G-quadruplex-forming sequences are

11 universal to chordates (Table S.2). Several chordate species present G-quadruplex-forming

12 sequences in tentacles other than ES7 (Table S.2). 
bioRxiv preprint doi: https://doi.org/10.1101/435594; this version posted November 16,2018 . The copyright holder for this preprint (which was not certified by peer review) is the author/funder, who has granted bioRxiv a license to display the preprint in perpetuity. It is made available under aCC-BY-NC-ND 4.0 International license.

\section{G-quadruplexes on the human 28S rRNA}

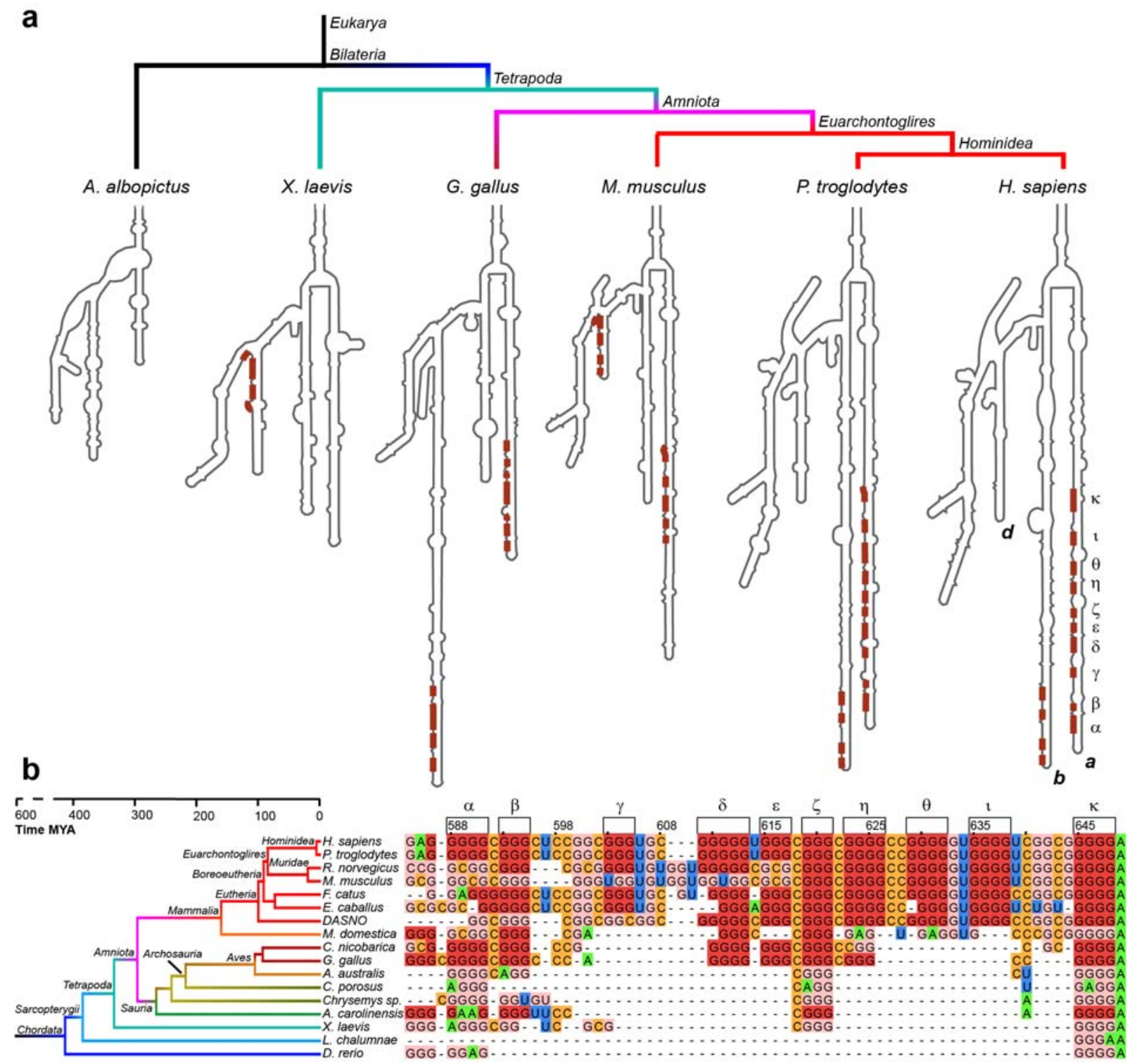

Figure 5. G-tracts in tentacle $a$ are observed in birds and mammals. a) Secondary structural models of ES7 from various eukaryotes. G-tracts with $\mathrm{G}_{\geq 3} \mathrm{~N}_{1-7} \mathrm{G}_{23} \mathrm{~N}_{1-7} \mathrm{G}_{\geq 3} \mathrm{~N}_{1-7} \mathrm{G}_{\geq 3}$ are highlighted in red. b) Sequence alignment of tentacle a showing conservation of G-quadruplex-forming sequences in chordates. G-tracts in both panels are labeled with Greek symbols. Nucleotides are colored by type. G's within G-tracts are dark red. Other G's are light red. All nucleotides are numbered in accordance with H. sapiens $28 \mathrm{~S}$ rRNA. Sizes of eukaryotic ES7 secondary structures are not to scale. Complete species nomenclature is provided in Table S.3.

Absence of G-quadruplex sequences in non-chordate rRNAs. To determine the phylogenic distribution of G-quadruplexes in LSU rRNA, we inspected highly curated sequences of 20 non-chordate eukaryotes from the SEREB database [1]. Thus far we can find no evidence of G-quadruplex-forming sequences in non-chordate eukaryotes. 
G-quadruplexes on the human 28S rRNA

RNA remodeling proteins bind selectively to rRNA G-quadruplexes. The

2 localization of rRNA G-quadruplex sequences on ribosomal surfaces would suggest they

3 interact with non-ribosomal proteins. To identify the proteins that bind to rRNA G-

4 quadruplexes, we performed pull-down experiments using stable isotope labeling with

5 amino acids in cell culture (SILAC). We focused on GQES7-1, the longest and most stable G-

6 quadruplex-forming region in human rRNA (Figure 6). GQES7-1 rRNA was linked on the 3'

7 end to biotin (GQES7-1-Biotin) and interacting proteins from human cell lysates were

8 pulled down and analyzed by mass spectrometry. The biotinylation of GQES7-1 did not

9 disrupt the G-quadruplexes (Figure S.3). Several known G-quadruplex-binding proteins

10 were pulled down by this assay (CNBP, YBOX1, hnRP F, hnRP H, DDX21, DDX17, DDX3X)

11 [27-33]. A significant number of helicases were identified (DDX3, CNBP, DDX21, DDX17),

12 all of which have been reported to unfold G-quadruplexes. In addition, a significant number

13 of heterogeneous nuclear ribonucleoproteins (hnRNPs) were bound to GQES7-1, including

14 hnRNP G-T/RMXL2, hnRNP M, hnRNP G/RBMX, hnRNP H2, hnRNP H, hnRNP F, hnRNP H3,

15 and FUS. hnRNPs are a family of RNA-binding proteins with functions including pre-mRNA

16 processing and transport of mRNAs to ribosomes [34]. Several of these proteins have been

17 previously identified as ribosome-binding proteins [35].

To support results of the pull-down experiments, Western blotting was performed

19 with four of the resulting proteins (Figure 6d). We assayed a DEAD-box RNA helicase

20 (DDX3X), a heterogeneous nuclear ribonucleoprotein (hnRNP H), the RNA-binding protein

21 FUS, and a pre-mRNA polyadenylation stimulator (FIP1). hnRNP H and DDX3X have been

22 previously identified as G-quadruplex-binding proteins. However, all four proteins are seen

23 to bind to GQES7-1 in the Western blot, suggesting we have tapped an uncharacterized pool

24 of G-quadruplex-binding proteins. 


\section{G-quadruplexes on the human 28S rRNA}

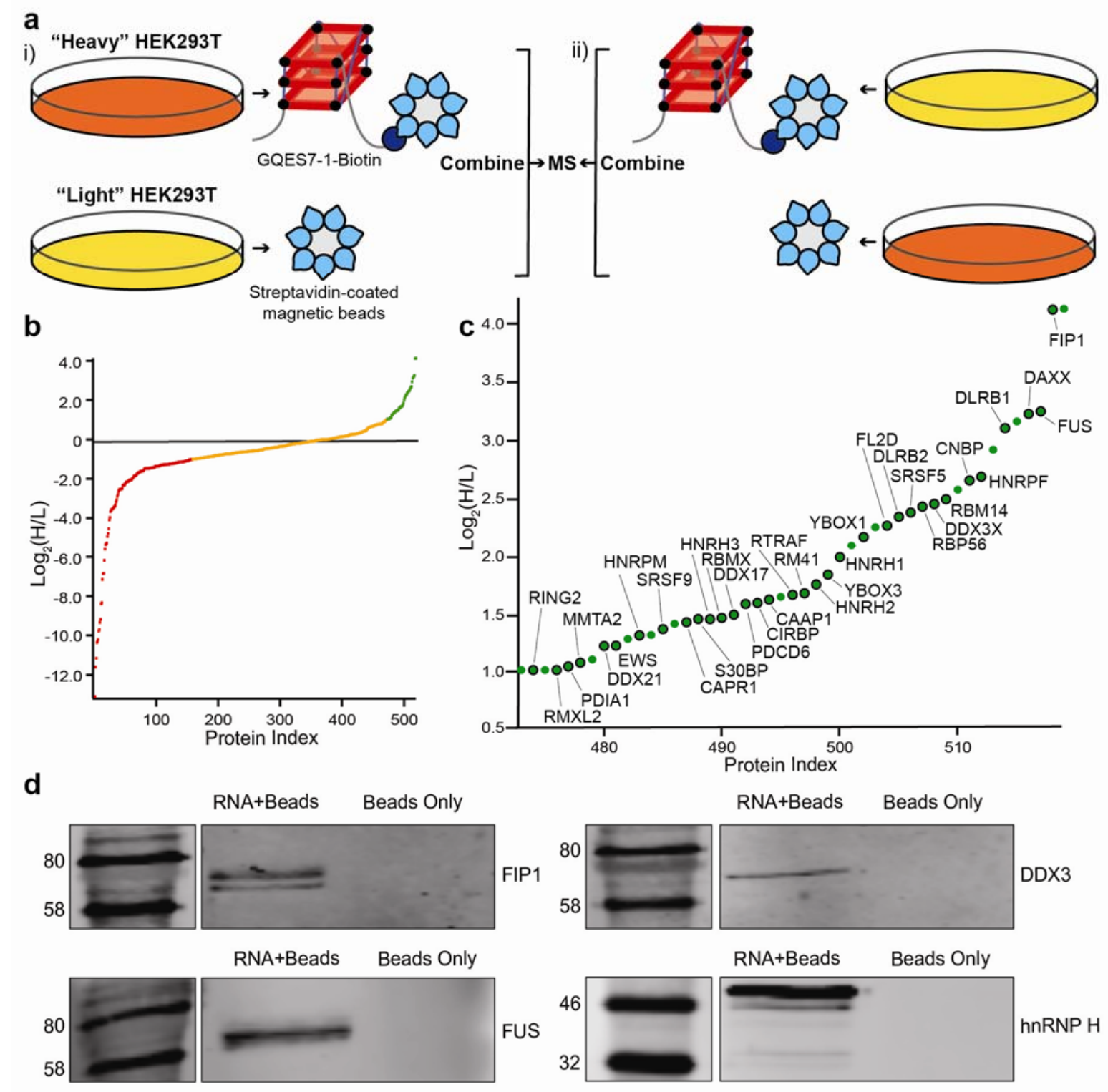

Figure 6. Identification of GQES7-1-binding proteins. a) Scheme of SILAC experiment. "RNA+beads" samples were combined in HEK293T grown in heavy media (i). The "Beads Only" control sample was combined in HEK293T grown in light media. To verify the proteins identified by this method, the experiment was performed using reverse labeling (ii). b) Scatter plot representing fold enrichment of the proteins binding to GQES7-1 in "Heavy" HEK293T. Color representation indicates specific proteins that bound more tightly to GQES7-1 than to the beads (green), to the beads than to GQES7-1 (red) or bound to the beads and GQES7-1 to a similar extent (orange). c) A close-up of the green region of the scatter plot represented in b). Dots with a black contour are used to indicate proteins that appeared in the green region of the two replicate experiments described in a). d) Western blotting analyses of the eluted proteins from the RNA pull-down of HEK293T. All four blotted proteins (FIP1, FUS, DDX3 and hnRNP H) eluted from the GQES7-1 sample (RNA+Beads) but not from the control (Beads Only), confirming the SILAC results. 
G-quadruplexes on the human 28S rRNA

\section{DISCUSSION}

RNA G-quadruplexes have been studied predominantly in the context of mRNAs, where they have been shown to help regulate expression of certain proteins. The results presented in this study indicate that the human LSU rRNA, one of the most abundant RNAs, contains sequences capable of forming G-quadruplexes (Figure 7). Computation, in vitro ThT fluorescence, CD spectroscopy, EMSAs, nuclease digestion and blotting with a Gquadruplex antibody provide a consistent picture of the propensities of G-quadruplex formation in the human 28S rRNA. Our phylogenetic analysis suggests that the $28 \mathrm{~S}$ rRNAs of all chordate ribosomes contain G-quadruplex-forming sequences near the termini of ES7 tentacle a. Our results suggest that nature's most complex organisms have evolved long rRNA tentacles with unexpected polymorphism, including the ability to convert to Gquadruplexes. At the limit, these sequences can be hundreds of Ångströms from the ribosomal core, suggesting roles in recruiting specific proteins or in stabilizing polysomes.

G-quadruplex-forming rRNA sequences appear to be a general feature of ribosomes of the phylum Chordata. We have inferred this by multiple sequence alignments. The specific sequences and exact locations of the G-quadruplexes on the tentacles are variable across phylogeny. We searched the SEREB database and could find no evidence of Gquadruplex-forming sequences outside of the Chordata phylum. The SEREB database is specifically designed for rRNA analysis, and includes species from all major phyla, and samples the tree of life in a sparse, efficient and accurate manner [1]. It contains complete and highly curated rRNA sequences.

To our knowledge, the possibility that rRNA can be loci of G-quadruplexes has not been investigated previously. G-quadruplex-forming sequences have been described in genes encoding for rRNA, where they are proposed to influence transcription [36] and bind to the nucleolar protein nucleophosmin [37]. However, these studies have focused on the external and internal transcribed regions (ETS and ITS) and are not part of the assembled ribosome. RNA G-quadruplexes have been observed previously in the cytoplasm of human cells [23] and are known to bind tightly to a wide variety of proteins. 


\section{G-quadruplexes on the human 28S rRNA}

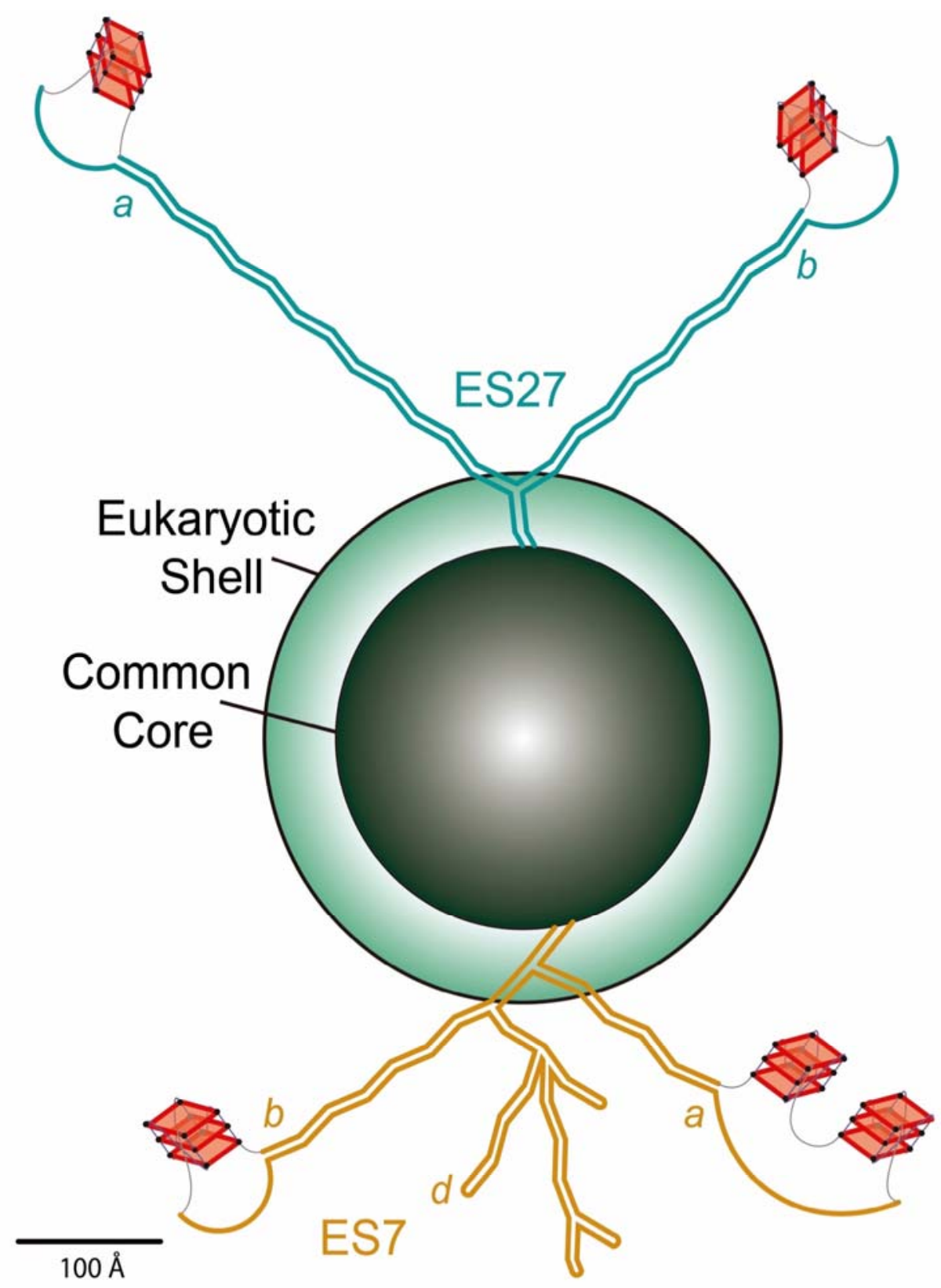

Figure 7. Schematic representation of the common core, the eukaryotic shell and the tentacles of metazoan ribosomes. G-quadruplexes are indicated on the tentacles of ES7 and ES27 in the LSU of the Homo sapiens ribosome. The lengths of ES7 $7_{\mathrm{HS}}$ (orange) and ES27 $7_{\mathrm{HS}}$ (green) tentacles are roughly scaled to the size of the common core. Tentacles $a, b$, and $d\left(\mathrm{ES}_{\mathrm{HS}}\right)$ and tentacles $a$ and $b\left(\mathrm{ES} 27_{\mathrm{HS}}\right)$ are indicated. Tentacle $a$ of ES7 is represented as two G-quadruplexes based on our results, which indicate more extensive and/or more stable G-quadruplexes than those found in tentacle $b$. The Gquadruplex region found in Helix 63 of $\mathrm{ES} 27_{\mathrm{HS}}$ is not represented here. The G-quadruplexes represented in tentacle $b$ of ES27 $7_{\mathrm{HS}}$ do not fall within the $\mathrm{G}_{\geq 3} \mathrm{~N}_{1-7} \mathrm{G}_{\geq 3} \mathrm{~N}_{1-7} \mathrm{G}_{\geq 3} \mathrm{~N}_{1-7} \mathrm{G}_{\geq 3}$ motif but this region contains extensive G-tracts (Table 1) that could form G-quadruplexes. 
The extent to which G-quadruplexes form in the context of cellular environments remains uncertain. Bartel and coworkers have suggested that mRNA G-quadruplexes are globally unfolded in eukaryotic cells, presumably by a mechanism involving regulated unwinding factors [38]. These experiments focused on poly-adenylated mRNAs rather than rRNAs, but these unwinding factors may influence G-quadruplexes in rRNA as well.

The preferential localization of rRNA G-quadruplex regions near the termini of specific tentacles of ES7 and ES27 suggests these regions as loci for specific cytosolic proteins. Here we identified multiple human RNA helicases and other RNA remodeling proteins that bind to rRNA G-quadruplexes. These proteins could be participants in Gquadruplex regulation on ribosomes.

Our observation that polysomes appear to form more extensive G-quadruplexes than monomer ribosomes suggests a role for intermolecular G-quadruplexes in closely associated ribosomes. Our work points to the possibility that, inside cells, ribosomes present polymorphic tentacles that can switch between unimolecular and multimolecular

15 G-quadruplexes and duplex forms. In this model, surfaces of ribosomes contain fluid 16 docking sites for G-quadruplex-specific proteins and foci for nucleic acid assemblies,

17 including in polyribosomes. In addition, it has been shown that G-quadruplexes can form phase separated gels in the absence of protein components [39]. It is conceivable that polysomes are surrounded by disordered RNA gels, contributed by ribosomal tentacles and stabilized by heterogeneous G-quadruplexes.

The experiments presented in this study were performed in a cell-free environment.

22 The extent to which rRNA G-quadruplexes form inside cells as well as their specific cellular

23 functions remain to be determined. The 5'-UTR of NRAS, one of the most widely studied G-

24 quadruplex-forming RNAs, contains four tandem G-tracts that have been reported to form

25 G-quadruplexes both in vitro and in cells $[33,40]$. We have identified ten tandem G-tracts in

26 tentacle $a$ of human ES7 rRNA and four in tentacle b. Our results indicate that these G-tracts

27 form stable G-quadruplexes in vitro. Considering that rRNA represents over $80 \%$ of the

28 total RNA in cells, our observation of rRNA G-quadruplexes significantly expands the 29 possibilities for participation of G-quadruplexes in biological processes. Recent studies 30 used G-quadruplex-RNA-specific precipitation to pull down rRNA from human cells [40]. 
G-quadruplexes on the human 28S rRNA

Together, the results presented here highlight that the increase in size in rRNA expansion segments of humans has been complemented with the capability of forming Gquadruplexes. The observation of rRNA G-quadruplex regions across the phylum Chordata

4 indicates potentially conserved functions, which most probably involve the association of 5 specific proteins and/or assembly of polysomes.

\section{METHODS}

ES7 $_{\mathrm{HS}}$ spans nucleotides 436 to 1311 of the $H$. sapiens LSU rRNA and contains sequences that we call GQES7-1 (nts 583-652) and GQES7-2 (nts 825-853). RNAs corresponding to ES7 $\mathrm{HS}, \mathrm{GQES7-1}$ and GQES7-2 were synthesized in vitro by transcription (HiScribe ${ }^{\mathrm{TM}}$ T7 High Yield RNA Synthesis Kit, New England Biolabs). $m t E S 7-1$ and $m t E S 7-2$ were ordered as RNA oligomers. Baker's yeast tRNAs were purchased from Roche. RNA purity was monitored by $8 \mathrm{M}$ Urea 5\% acrylamide gel in TBE buffer. Complete sequences of ES7 $_{\mathrm{HS}}$ GQES7-1, GQES7-2, $m t$ ES7-1 and $m t$ ES7-2 are contained in Table S.1.

HEK293T 28S rRNA extraction and purification. HEK293T cells were grown to $60 \%$ confluency after which total RNA was extracted with TRI Reagent $($ (Sigma-Aldrich). 28S rRNA was extracted from an agarose gel by running the rRNA into wells in the center of the gel, where the rRNA was extracted with a pipette. The rRNA was precipitated in $5 \mathrm{M}$ ammonium acetate-acetic Acid, pH 7.5 with excess ethanol. 28S rRNA purity was monitored on 1\% agarose gels (Figure S.1).

Thioflavin T (ThT) fluorescence. RNAs were prepared at a final concentration of $0.6 \mu \mathrm{M}$ (strand) and annealed in $150 \mathrm{mM} \mathrm{KCl,} 10 \mathrm{mM}$ Tris- $\mathrm{HCl}, \mathrm{pH}$ 7.5, $2 \mu \mathrm{M}$ ThT by cooling

23 from $90^{\circ} \mathrm{C}$ to $25^{\circ} \mathrm{C}$ at $1^{\circ} / \mathrm{min}$. RNAs were incubated at $4^{\circ} \mathrm{C}$ for $10 \mathrm{~min}$ and were loaded onto

24 a Corning® 384 Well Flat Clear Bottom Microplate. Fluorescence from 300-700 nm, 25 exciting at $440 \mathrm{~nm}$ were acquired on a BioTek Synergy ${ }^{\mathrm{TM}}$ H4 Hybrid plate reader. When 26 appropriate, pyridostatin (PDS) was added to the desired concentration after the RNA was 27 annealed.

Circular dichroism. RNA at $2 \mu \mathrm{M}$ (strand) in $50 \mathrm{mM} \mathrm{KCl}$ and $10 \mathrm{mM}$ Tris- $\mathrm{HCl}$ (pH 7.5) was annealed as described above. CD spectra were acquired at $20^{\circ} \mathrm{C}$ on a Jasco J-810 spectropolarimeter using $1 \mathrm{~mm}$ cuvettes. Data from 200-320 nm was acquired at a rate of 
G-quadruplexes on the human 28S rRNA

$1100 \mathrm{~nm} / \mathrm{min}$ with $1 \mathrm{sec}$ response, a bandwidth of $5 \mathrm{~nm}$, and averaged over three

2 measurements. The buffer spectrum was subtracted. Smoothing was performed with Igor

3 Pro. The observed ellipticity $(\theta$, mdeg) was normalized [41] using the expression

$4 \Delta \varepsilon=\theta /(32,980 \times c \times l)$, where $c$ is the molar strand concentration of the RNA and $l$ is

5 the path length of the cuvette in centimeters.

$6 \quad$ Ion-dependent electrophoresis. Aliquots of RNAs at $1 \mu \mathrm{M}$ (strand) were annealed

7 in the presence of either $\mathrm{Na}^{+}$or $\mathrm{Li}^{+}$or $\mathrm{K}^{+}$at various concentrations (50 mM, $100 \mathrm{mM}, 250$

$8 \mathrm{mM}$ ) in $10 \mathrm{mM}$ Tris- $\mathrm{HCl}, \mathrm{pH}$ 7.5. Samples were mixed with glycerol (50\%) and resolved on

$95 \%$ native acrylamide gels, which were stained for $15 \mathrm{~min}$ in $0.5 \mu \mathrm{M}$ ThT and imaged on an

10 Azure imager c400 (Azure Biosystems).

11 EMSAs. The anti-G-quadruplex BG4 antibody was purchased from Absolute

12 Antibody (Catalog \#: Ab00174-1.1). GQES7-1 (3 $\mu \mathrm{M}$ ) rRNA or the negative control $m t$ ES7-1

13 RNA were annealed in 20 mM Hepes-Tris, pH 7.5, 50 mM KCl. GQES7-1 rRNA or mtES7-1

14 RNA were combined with various concentrations of BG4 at a final RNA concentration of 1

$15 \mu \mathrm{M}$ RNA (strand). RNA-protein mixtures were incubated at room temperature for $20 \mathrm{~min}$ in

$1650 \mathrm{mM} \mathrm{KCl}$. RNA-protein interactions were analyzed by 5\% native-PAGE. Gels were

17 visualized following a dual fluorescent dye protocol [42] with a Azure imager c400 (Azure

18 Biosystems).

rRNA - BG4 antibody dot blotting. RNAs were annealed in the presence of $50 \mathrm{mM}$

$20 \mathrm{KCl}$ and were diluted $1 \mathrm{x}, 2 \mathrm{x}$ and 4x. GQES7-1, GQES7-2, mtES7-2, tRNA: $3.2 \mu \mathrm{M}, 1.6 \mu \mathrm{M} 0.8$

$21 \mu \mathrm{M} . \mathrm{ES7}_{\mathrm{HS}}: 1.4 \mu \mathrm{M}, 0.7 \mu \mathrm{M}, 0.35 \mu \mathrm{M}$. 28S rRNA: $55 \mathrm{nM}, 27.5 \mathrm{nM}, 13.7 \mathrm{nM}$. RNAs were loaded

22 onto nitrocellulose membranes and dried at room temperature for $30 \mathrm{~min}$. RNAs were

23 cross-linked with the membrane in a GS Gene Linker ${ }^{\mathrm{TM}}$ UV Chamber (Bio Rad). The

24 membranes were blocked for $1 \mathrm{~h}$ at room temperature. BG4 antibody was added (1:2,000

25 dilution) and incubated with gentle rocking for sixty min at room temperature. The

26 membrane was washed for ten min twice with 1X TBST and incubated for sixty min with an

27 appropriate fluorescent secondary antibody anti-mouse (1:10,000 dilution) (Biotium,

28 \#20065-1). The membrane was washed for ten min twice with 1X TBST and was imaged on

29 a Li-Cor Odyssey Blot Imager. Intact $80 \mathrm{~S}$ ribosomes and polysomes were purified from

30 HEK293, which were incubated $5 \mathrm{~min}$ in $10 \mu \mathrm{g} / \mathrm{mL}$ cycloheximide at $37^{\circ} \mathrm{C}$. Lysis buffer $(10$ 
$1 \mathrm{mM} \mathrm{NaCl}, 10 \mathrm{mM} \mathrm{MgCl} 2,10 \mathrm{mM}$ Tris-HCl, $\mathrm{pH}$ 7.5, 1\% Triton $\mathrm{X}-100,1 \%$ sodium 2 deoxycholate, $0.2 \mathrm{U} / \mathrm{mL}$ DNase I, RNase inhibitor, $1 \mathrm{mM}$ dithiothreitol, $10 \mu \mathrm{g} / \mathrm{mL}$ 3 cycloheximide) was used to scrap the cells. Nuclei and cell debris were removed by 4 centrifugation and the supernatant was transferred to a 15-50\% sucrose gradient 5 containing $100 \mathrm{mM} \mathrm{NaCl}, 10 \mathrm{mM} \mathrm{MgCl}_{2}, 30 \mathrm{mM}$ Tris- $\mathrm{HCl}, \mathrm{pH} 7.5$ and centrifuged by 6 ultracentrifugation. Purified 80S ribosomes and polysomes were then incubated at room 7 temperature for $15 \mathrm{~min}$ in the presence of $50 \mathrm{mM} \mathrm{KCl}$ with or without $10 \mu \mathrm{M}$ PDS. 8 Ribosomes or polysomes were added iteratively in 30-min intervals to the same site on a 9 nitrocellulose membrane $(0.9 \mu \mathrm{g}, 2.7 \mu \mathrm{g}, 4.5 \mu \mathrm{g})$. The membrane was then treated as 10 described above. BG4 was added to a final dilution of 1:1,000 and the secondary antibody 11 was added to a final dilution of 1:5,000.

12 Mung bean nuclease (MBN) probing. ES7 ${ }_{\mathrm{HS}}$ and tRNA were prepared at $100 \mathrm{ng} / \mu \mathrm{L}$ 13 and annealed in the presence/absence of $100 \mathrm{mM} \mathrm{KCl}, 15 \mathrm{mM}$ Tris- $\mathrm{HCl}(\mathrm{pH} \mathrm{7.5)}$ by cooling 14 from $90^{\circ} \mathrm{C}$ to $25^{\circ} \mathrm{C}$, at $1 \%$ min. PDS was added to the annealed RNA to a final concentration 15 of $2 \mu \mathrm{M}$. One unit of MBN was added per $\mu \mathrm{g}$ of RNA and samples were incubated at $30^{\circ} \mathrm{C}$ for $1630 \mathrm{~min}$. SDS was added to a final concentration of $0.01 \%$ to denature the nuclease and RNA 17 was purified by ethanol precipitation. The extent of RNA cleavage was determined on an 8 18 M urea 5\% acrylamide (19:1 acrylamide/bisacrylamide) gel stained with ethidium 19 bromide.

ES7 secondary structures. Secondary structures of human and D. melanogaster

22 troglodytes, M. musculus and G. gallus (Table 1) were numbered as in Bernier [1], 23 subtracting the nucleotides from the 5.8S rRNA.

Phylogeny and Multiple Sequence Alignments. The SEREB MSA [1] was used as a seed to align additional eukaryotic ES7 sequences to increase the density of eukaryotic 26 species in the MSA. The 28S rRNA sequences in the SEREB MSA were used to search [44] 27 the NCBI databases [45] for LSU rRNA sequences. The SEREB database has sequences from 2810 chordate species; seven additional chordate species from 7 new orders were added to 29 the ES7 tentacle a MSA (Figure 7, Table S.3). Sequences without intact ES7 tentacle a were excluded. Sequences with partial 28S rRNA were marked as partial. Sequences inferred 
1 from genomic scaffolds were marked as predicted (Table S.3). The extended database was 2 queried for G-quadruplex-forming sequences.

Sequences were incorporated into the SEREB-seeded MSA using MAFFT [46] and 4 adjusted manually using BioEdit [47]. Manual adjustments incorporated information from 5 available secondary structures. In some cases, the positions of G-tracts in sequences with 6 large gaps relative to $H$. sapiens are not fully determined, as they can be aligned equally 7 well with flanking G-tracts in the MSA. Alignment visualization was done with Jalview [48]. 8 The phylogenetic tree and the timeline of clade development were inferred from TimeTree 9 [49].

Analysis of the entire LSU was performed on SEREB sequences, which are highly

11 curated and always complete. This procedure ensured that negative results indicate 12 absence of G-quadruplex-forming sequences from intact rRNAs rather than absence from 13 rRNA fragments that lack the appropriate regions. G-quadruplex-forming sequences are 14 not detected in any of the 20 non-chordate members of the SEREB database.

SILAC. HEK293T cells were cultured in SILAC media - "heavy" or "light" Dulbecco's Miodified Eagle Media (DMEM) (Thermo Scientific) supplemented with 10\% dialyzed fetal

17 bovine serum (FBS) (Corning) and 1\% penicillin-streptomycin solution (Sigma) in a humidified incubator at $37{ }^{\circ} \mathrm{C}$ with $5 \%$ carbon dioxide. The heavy media contained 0.798 $\mathrm{mM}$ L-lysine $\left({ }^{13} \mathrm{C}_{6}\right.$ and ${ }^{15} \mathrm{~N}_{2}$, Cambridge Isotope Laboratories) and $0.398 \mathrm{mM}$ L-arginine $\left({ }^{13} \mathrm{C}_{6}\right.$, Cambridge Isotope Laboratories). The light media had the same concentrations of normal lysine and arginine (Sigma). Media were supplemented with $0.2 \mathrm{mg} / \mathrm{mL}$ proline

22 (Sigma) to prevent arginine-to-proline conversion. Heavy and light cells were grown for at 23 least six generations. Once the confluency reached $80 \%$, cells were harvested by scraping, 24 washed twice with ice-cold PBS (Sigma), lysed in a buffer containing $10 \mathrm{mM}$ HEPES pH=7.4, $25200 \mathrm{mM}$ potassium chloride, 1\% Triton X-100, $10 \mathrm{mM}$ magnesium chloride (all from Sigma) 26 and 1 pill/10 mL c0mplete ULTRA tablet protease inhibitor (Roche), and incubated on an 27 end-over-end shaker at $4{ }^{\circ} \mathrm{C}$ for 1 hour. Lysates were centrifuged at $25,830 \mathrm{~g}$ at $4{ }^{\circ} \mathrm{C}$ for 10 28 minutes, and the supernatants were collected and kept on ice.

Ten $\mu \mathrm{g}$ of GQES7-1-Biotin RNA was annealed as described above in the presence of $3010 \mathrm{mM}$ Tris- $\mathrm{HCl}, \mathrm{pH}$ 7.5, and $100 \mathrm{mM} \mathrm{KCl}$. Twenty $\mu \mathrm{L}$ of magnetic streptavidin-coated beads 
G-quadruplexes on the human 28S rRNA

1 (GE Healthcare) were washed with Lysis buffer (10 mM HEPES, pH 7.4, $200 \mathrm{mM} \mathrm{KCl,} \mathrm{1 \%}$

2 Triton $\mathrm{X}-100,10 \mathrm{mM} \mathrm{MgCl}$, protease inhibitors). Annealed RNA was then added to the

3 washed beads and incubated at $4^{\circ} \mathrm{C}$ for $30 \mathrm{~min}$ with gentle shaking. For control

4 experiments, no RNA was added. SILAC cell lysates were incubated with $0.5 \mathrm{mg}$ E. coli tRNA

5 per $1 \mathrm{mg}$ protein at $4^{\circ} \mathrm{C}$ for $30 \mathrm{~min}$ with gentle shaking. "RNA+Beads" and control "Beads

6 Only" samples were transferred into the SILAC cell lysates: "RNA+Beads" were added to the

7 Heavy cell lysate and “Beads Only” was added to "Light” HEK293T cell lysate. As a replicate,

8 "RNA+Beads" was added "Light" cell lysate and "Beads Only" was added to "Heavy" cell

9 lysate. $200 \mathrm{U} / \mathrm{mL}$ of RNasin was added and the lysates were incubated at $4{ }^{\circ} \mathrm{C}$ for 2 hrs with

10 gentle shaking. Samples were centrifuged, the supernatant was discarded, and the pelleted

11 beads were washed with lysis buffer with increasing $\mathrm{KCl}$ concentrations $(0.4 \mathrm{M}, 0.8 \mathrm{M}, 1.6$

$12 \mathrm{M})$. After the three washes, $100 \mu \mathrm{L}$ of the elution buffer (100 mM Tris-HCl, pH 7.4, 1\% SDS,

$13100 \mathrm{mM}$ DTT) was added to one of the two samples and then combined with the beads of

14 the corresponding sample. "RNA+Beads" in "Heavy" lysates were combined with "Beads

15 Only" in "Light" lysates and "RNA+Beads" in "Light" lysates were combined with "Beads

16 Only" in "Heavy" lysates. The combined samples were boiled and then briefly centrifuged.

17 Beads were discarded and samples were analyzed with an online LC-MS system.

Mass spectrometry analyses. Eluted proteins were diluted 10 times with $50 \mathrm{mM}$ HEPES pH=7.4 and were alkylated with $28 \mathrm{mM}$ iodoacetamide (Sigma) for 30 minutes at room temperature in the dark. Proteins were precipitated by methanol-chloroform, and the

21 pellets were resuspended in digestion buffer containing $50 \mathrm{mM}$ HEPES pH=8.8, 1.6 M urea,

22 and 5\% acetonitrile (ACN) (all from Sigma). After digestion with sequencing-grade

23 modified trypsin (Promega) at $37{ }^{\circ} \mathrm{C}$ for 16 hours, reactions were quenched with $1 \%$

24 trifluoroacetic acid (TFA, Fisher Scientific) and purified with StageTip. Peptides were 25 dissolved in $10 \mu \mathrm{L} \mathrm{5 \%} \mathrm{ACN} \mathrm{and} \mathrm{4 \%} \mathrm{FA} \mathrm{solution,} \mathrm{and} 1 \mu \mathrm{L}$ was loaded to a Dionex UltiMate 263000 UHPLC system (Thermo Fisher Scientific) with a microcapillary column packed in-

27 house with C18 beads (Magic C18AQ, 5 mm, $200 \AA \AA, 100 \mathrm{~mm} 16 \mathrm{~cm}$ ). A 110-minute gradient 28 of $3-22 \%$ ACN containing $0.125 \%$ FA was used. The peptides were detected with an LTQ 29 Orbitrap Elite Hybrid Mass Spectrometer (Thermo Fisher Scientific) controlled by Xcalibur 30 software (version 3.0.63). MS/MS analysis was performed with a data-dependent Top20 
1 method. For each cycle, a full MS scan in the Orbitrap with the automatic gain control (AGC)

2 target of $10^{6}$ and the resolution of 60,000 at $400 \mathrm{~m} / \mathrm{z}$ was followed by up to $20 \mathrm{MS} / \mathrm{MS}$

3 scans in the LTQ for the most intense ions. Selected ions were excluded from further

4 sequencing for 90 seconds. Ions with singly or unassigned charge were not sequenced.

5 Maximum ion accumulation times were 1,000 ms for each full MS scan and $50 \mathrm{~ms}$ for each

6 MS/MS scans. The spectra were searched against a human protein database downloaded

7 from UniProt using the SEQUEST algorithm (version 28) [50]. The following parameters

8 were used: 20 ppm precursor mass tolerance; 1.0 Da fragment ion mass tolerance; trypsin

9 digestion; maximum of 3 missed cleavages; differential modifications for methionine

10 oxidation (+15.9949 Da), heavy lysine (+8.0142 Da), and heavy arginine (+6.0201 Da);

11 fixed modification for cysteine carbamidomethylation (+57.0215 Da). The false discovery

12 rates (FDR) were evaluated and controlled by the target-decoy method. Linear

13 discriminant analysis (LDA) was used to filtered the peptides to $<1 \%$ FDR based on

14 parameters such as XCorr, differential sequence $\Delta C_{n}$, and precursor mass error. An

15 additional filter was used to control the protein FDR to $<1 \%$. For SILAC quantification, the

$16 \mathrm{~S} / \mathrm{N}$ ratios of both heavy and light peptides must be greater than 3. Otherwise, one of the

17 two versions of the peptides (heavy or light) must have the S/N ratio greater than 10. Other

18 peptides that did not pass these criteria were removed. The final protein ratio was

19 calculated from the median value of the peptides from each parent protein. The raw files

20 are publicly accessible at http://www.peptideatlas.org/PASS/PASS01260, Username:

21 PASS01260, Password: TL3854zn.

22 Western Blotting. Samples were electrophoresed on 12\% SDS-PAGE gels and

23 transferred to a nitrocellulose membrane overnight. Membranes were blocked for 1 hour

24 at room temperature with gentle shaking and then incubated for another hour with

25 primary antibodies: 1:200 dilution of FIP1 (mouse monoclonal, sc-398392), DDX3 (mouse

26 monoclonal, sc-81247), FUS (mouse monoclonal, sc-47711), or hnRNP H (mouse

27 monoclonal, sc-32310). Antibodies were obtained from Santa Cruz Biotechnology.

28 Membranes were washed three times with 1X TBST and secondary antibody CF680 goat

29 anti-mouse IgG (H+L) (Biotium, 20065) was added (1:5,000 dilution). Membranes were

30 washed three times with 1X TBST and imaged on a Li-Cor Odyssey Blot Imager. 
G-quadruplexes on the human 28S rRNA

\section{ACKNOWLEDGEMENTS}

3 The authors thank Dr. Jonathan B. Chaires for helpful discussions and Dr. Lizzette M. Gómez

4 Ramos for designing the negative G-quadruplex controls. Purified 80S ribosomes and 5 polysomes were a gift from Immagina BioTechnology. This work was supported by NASA 6 (NNX16AJ28G and NNX16AJ29G to LDW) and the National Institutes of Health 7 (R01GM118803 to RW).

9 CONFLICT OF INTEREST

10 The authors declare that they have no conflict of interest with the contents of this article.

\section{AUTHOR CONTRIBUTIONS}

13 SMF, SS, CI, ASP, RMW, RW, and LDW conceived and designed the experiments; SMF, SS and

14 CI performed the experiments; ASP and PIP conducted the phylogenetic analysis. SMF, PIP, 15 SS, ASP, RMW, RW, and LDW analyzed data; SMF, PIP, SS and LDW prepared figures; and 16 SMF, PIP and LDW wrote the paper.

\section{REFERENCES:}

[1] Bernier CR, Petrov AS, Kovacs NA, Penev PI, Williams LD. Translation: The universal structural core of life. Mol. Biol. Evol. 2018;34:2065-76.

22 [2] Ware VC, Tague BW, Clark CG, Gourse RL, Brand RC, Gerbi SA. Sequence analysis of 28S

23 ribosomal DNA from the amphibian Xenopus laevis. Nucleic Acids Res. 1983;11:7795-817.

24 [3] Clark CG, Tague BW, Ware VC, Gerbi SA. Xenopus laevis 28S ribosomal RNA: A secondary 25 structure model and its evolutionary and functional implications. Nucleic Acids Res.

26 1984;12:6197-220.

27 [4] Hassouna N, Michot B, Bachellerie JP. The complete nucleotide sequence of mouse 28S 28 rRNA gene. Implications for the process of size increase of the large subunit rRNA in higher 29 eukaryotes. Nucleic Acids Res. 1984;12:3563-83.

30 [5] Gerbi SA. Expansion segments: Regions of variable size that interrupt the universal core secondary structure of ribosomal RNA. In: Zimmermann RA, Dahlberg AE, editors.

32 Ribosomal RNA-structure, evolution, processing, and function in protein synthesis. Boca 


\section{G-quadruplexes on the human 28S rRNA}

1 [6] Ramesh M, Woolford JL, Jr. Eukaryote-specific rRNA expansion segments function in

2 ribosome biogenesis. RNA. 2016;22:1153-62.

3 [7] Leidig C, Bange G, Kopp J, Amlacher S, Aravind A, Wickles S, et al. Structural

4 characterization of a eukaryotic chaperone--the ribosome-associated complex. Nat. Struct.

5 Mol. Biol. 2013;20:23-8.

6 [8] Gumiero A, Conz C, Gesé GV, Zhang Y, Weyer FA, Lapouge K, et al. Interaction of the 7 cotranslational hsp70 ssb with ribosomal proteins and rRNA depends on its lid domain.

8 Nat. Commun. 2016;7:13563.

9 [9] Melnikov S, Ben-Shem A, Garreau de Loubresse N, Jenner L, Yusupova G, Yusupov M.

10 One core, two shells: Bacterial and eukaryotic ribosomes. Nat. Struct. Mol. Biol.

$112012 ; 19: 560-7$.

12 [10] Huppert JL, Bugaut A, Kumari S, Balasubramanian S. G-quadruplexes: The beginning 13 and end of utrs. Nucleic Acids Res. 2008;36:6260-8.

14 [11] Eddy J, Maizels N. Conserved elements with potential to form polymorphic G-

15 quadruplex structures in the first intron of human genes. Nucleic Acids Res. 2008;36:1321-

1633.

17 [12] Kikin 0, D'Antonio L, Bagga PS. QGRS mapper: A web-based server for predicting G-

18 quadruplexes in nucleotide sequences. Nucleic Acids Res. 2006;34:W676-82.

19 [13] Lammich S, Kamp F, Wagner J, Nuscher B, Zilow S, Ludwig A-K, et al. Translational

20 repression of the disintegrin and metalloprotease ADAM10 by a stable G-quadruplex

21 secondary structure in its 5?-untranslated region. J. Biol. Chem. 2011;286:45063-72.

22 [14] Xu S, Li Q, Xiang J, Yang Q, Sun H, Guan A, et al. Thioflavin t as an efficient fluorescence

23 sensor for selective recognition of RNA G-quadruplexes. Scientific Reports. 2016;6.

24 [15] Renaud de la Faverie A, Guédin A, Bedrat A, Yatsunyk LA, Mergny J-L. Thioflavin t as a

25 fluorescence light-up probe for G4 formation. Nucleic Acids Res. 2014;42:e65-e.

26 [16] Zhang S, Sun H, Chen H, Li Q, Guan A, Wang L, et al. Direct visualization of nucleolar G-

27 quadruplexes in live cells by using a fluorescent light-up probe. Biochim Biophys Acta.

28 2018;1862:1101-6.

29 [17] von Hacht A, Seifert 0, Menger M, Schutze T, Arora A, Konthur Z, et al. Identification

30 and characterization of RNA guanine-quadruplex binding proteins. Nucleic Acids Res.

$312014 ; 42: 6630-44$.

32 [18] Fratta P, Mizielinska S, Nicoll AJ, Zloh M, Fisher EM, Parkinson G, et al. C9orf72

33 hexanucleotide repeat associated with amyotrophic lateral sclerosis and frontotemporal

34 dementia forms RNA G-quadruplexes. Scientific Reports. 2012;2:1016. 
1 [19] Halder K, Wieland M, Hartig JS. Predictable suppression of gene expression by 5'-UTR-

2 based RNA quadruplexes. Nucleic Acids Res. 2009;37:6811-7.

3 [20] Arora A, Dutkiewicz M, Scaria V, Hariharan M, Maiti S, Kurreck J. Inhibition of

4 translation in living eukaryotic cells by an RNA G-quadruplex motif. RNA. 2008;14:1290-6.

5 [21] Kumari S, Bugaut A, Huppert JL, Balasubramanian S. An RNA G-quadruplex in the 5'

6 UTR of the NRAS proto-oncogene modulates translation. Nat Chem. Biol. 2007;3:218-21.

7 [22] Choi KH, Choi BS. Formation of a hairpin structure by telomere 3' overhang. Biochim.

8 Biophys. Acta-Gene Struct. Expression. 1994;1217:341-4.

9 [23] Biffi G, Di Antonio M, Tannahill D, Balasubramanian S. Visualization and selective 10 chemical targeting of RNA G-quadruplex structures in the cytoplasm of human cells. Nat.

11 Chem. 2014;6:75-80.

12 [24] Biffi G, Tannahill D, McCafferty J, Balasubramanian S. Quantitative visualization of DNA

13 G-quadruplex structures in human cells. Nat. Chem. 2013;5:182-6.

14 [25] Cang X, Šponer J, Cheatham III TE. Explaining the varied glycosidic conformational, G15 tract length and sequence preferences for anti-parallel G-quadruplexes. Nucleic Acids Res.

16 2011;39:4499-512.

17 [26] Li X-m, Zheng K-w, Zhang J-y, Liu H-h, Yuan B-f, Hao Y-h, et al. Guanine-vacancy18 bearing G-quadruplexes responsive to guanine derivatives. Proc. Natl. Acad. Sci. USA. 19 2015;112:14581-6.

20 [27] Benhalevy D, Gupta SK, Danan CH, Ghosal S, Sun H-W, Kazemier HG, et al. The human 21 cchc-type zinc finger nucleic acid-binding protein binds g-rich elements in target mRNA 22 coding sequences and promotes translation. Cell Rep. 2017;18:2979-90.

23 [28] Khateb S, Weisman-Shomer P, Hershco-Shani I, Ludwig AL, Fry M. The tetraplex (CGG) 24 n destabilizing proteins hnRNP a 2 and cbf-a enhance the in vivo translation of fragile $\mathrm{x}$ 25 premutation mRNA. Nucleic Acids Res. 2007;35:5775-88.

26 [29] Matunis MJ, Xing J, Dreyfuss G. The hnRNP f protein: Unique primary structure, nucleic 27 acid-binding properties, and subcellular localization. Nucleic Acids Res. 1994;22:1059-67.

28 [30] Caputi M, Zahler AM. Determination of the RNA binding specificity of the 29 heterogeneous nuclear ribonucleoprotein (hnRNP) h/h? /f/2h9 family. J. Biol. Chem.

$30 \quad 2001 ; 276: 43850-9$.

31 [31] McRae EK, Booy EP, Padilla-Meier GP, McKenna SA. On characterizing the interactions 32 between proteins and guanine quadruplex structures of nucleic acids. J. Nucl. Acids.

$332017 ; 2017$. 
1 [32] Dardenne E, Espinoza MP, Fattet L, Germann S, Lambert M-P, Neil H, et al. RNA

2 helicases DDX5 and DDX17 dynamically orchestrate transcription, miRNA, and splicing

3 programs in cell differentiation. Cell Rep. 2014;7:1900-13.

4 [33] Herdy B, Mayer C, Varshney D, Marsico G, Murat P, Taylor C, et al. Analysis of NRAS

5 RNA G-quadruplex binding proteins reveals DDX3X as a novel interactor of cellular G-

6 quadruplex containing transcripts. Nucleic Acids Res. 2018.

7 [34] Chaudhury A, Chander P, Howe PH. Heterogeneous nuclear ribonucleoproteins

8 (hnRNPs) in cellular processes: Focus on hnRNP e1's multifunctional regulatory roles. RNA.

92010.

10 [35] Simsek D, Tiu GC, Flynn RA, Byeon GW, Leppek K, Xu AF, et al. The mammalian ribo-

11 interactome reveals ribosome functional diversity and heterogeneity. Cell. 2017;169:1051-

12 65. e18.

13 [36] Drygin D, Siddiqui-Jain A, O'Brien S, Schwaebe M, Lin A, Bliesath J, et al. Anticancer

14 activity of cx-3543: A direct inhibitor of rRNA biogenesis. Cancer Res. 2009;69:7653-61.

15 [37] Chiarella S, De Cola A, Scaglione GL, Carletti E, Graziano V, Barcaroli D, et al.

16 Nucleophosmin mutations alter its nucleolar localization by impairing G-quadruplex

17 binding at ribosomal DNA. Nucleic Acids Res. 2013;41:3228-39.

18 [38] Guo JU, Bartel DP. RNA G-quadruplexes are globally unfolded in eukaryotic cells and 19 depleted in bacteria. Science. 2016;353:aaf5371.

20 [39] Jain A, Vale RD. RNA phase transitions in repeat expansion disorders. Nature.

$21 \quad 2017 ; 546: 243-7$.

22 [40] Yang SY, Lejault P, Chevrier S, Boidot R, Robertson AG, Wong JM, et al. Transcriptome-

23 wide identification of transient RNA G-quadruplexes in human cells. Nat. Commun.

24 2018;9:4730.

25 [41] del Villar-Guerra R, Gray RD, Chaires JB. Characterization of quadruplex DNA structure

26 by circular dichroism. Curr. Protoc. Nucleic Acid Chem. 2017:17.8. 1-.8. 6.

27 [42] Shcherbakov D, Piendl W. A novel view of gel-shifts: Analysis of RNA-protein

28 complexes using a two-color fluorescence dye procedure. Electrophoresis. 2007;28:749-55.

29 [43] Bernier C, Petrov AS, Waterbury C, Jett J, Li F, Freil LE, et al. Ribovision: Visualization

30 and analysis of ribosomes. Faraday Discuss. 2014;169:195-207.

31 [44] Altschul SF, Madden TL, Schaffer AA, Zhang J, Zhang Z, Miller W, et al. Gapped blast and

32 psi-blast: A new generation of protein database search programs. Nucleic Acids Res.

33 1997;25:3389-402. 
1 [45] Database resources of the national center for biotechnology information. Nucleic Acids

2 Res. 2017;45:D12-d7.

3 [46] Katoh K, Standley DM. A simple method to control over-alignment in the MAFFT

4 multiple sequence alignment program. Bioinformatics. 2016;32:1933-42.

5 [47] Hall TA. Bioedit: A user-friendly biological sequence alignment editor and analysis

6 program for windows 95/98/nt. Nucleic Acids Symp. Ser.: [London]: Information Retrieval

7 Ltd., c1979-c2000.; 1999. p. 95-8.

8 [48] Waterhouse AM, Procter JB, Martin DM, Clamp M, Barton GJ. Jalview version 2-a

9 multiple sequence alignment editor and analysis workbench. Bioinformatics.

10 2009;25:1189-91.

11 [49] Hedges SB, Dudley J, Kumar S. Timetree: A public knowledge-base of divergence times

12 among organisms. Bioinformatics. 2006;22:2971-2.

13 [50] Eng JK, McCormack AL, Yates JR. An approach to correlate tandem mass spectral data 14 of peptides with amino acid sequences in a protein database. J Am Soc Mass Spectrom.

15 1994;5:976-89. 